\title{
PENGARUH INISIASI MENYUSU DINI (IMD) TERHADAP JUMLAH DARAH KALA IV PERSALINAN
}

\section{IRMA NURIANTI', TATI MURNI KARO-KARO², SRI MELDA BR BANGUN $^{3}$, SRI YANA ${ }^{4}$}

\author{
1,2,3,4INSTITUT KESEHATAN MEDISTRA LUBUK PAKAM \\ JL. SUDIRMAN NO 38 LUBUK PAKAM \\ e-mail: irmaiim22@yahoo.com
}

DOI : https://doi.org/10.35451/jkk.v2i2.394

\begin{abstract}
Early Breastfeeding Initiation (EBI) or the onset of early breastfeeding is to give newborns the opportunity to suckle themselves on their mothers in the first hour of birth, Early Breastfeeding Initiation (EBI) is related to the production of the hormone oxytocin, which helps the uterus contract so that it does not can immediately reduce bleeding in the mother. The Early Breastfeeding Initiation (EBI) itself is still low in Indonesia, North Sumatra contributes to the low rate of EBI implementation at 24\%, according to the Director General of Family Health of the Ministry of Health Eni Gustina. The biggest cause of maternal mortality in Indonesia during 2010-2013 was bleeding $30.3 \%$. The purpose of this study was to determine whether there was an effect of early breastfeeding initiation (EBI) on the amount of bleeding period IV in the midwife clinic Suherni Amd. Keb Kec Beringin kab Deli Serdang in 2019. This type of research is preexperiment with the design of static group comparison, with a population of 28 post partum mothers. Sampling is done by "purposive sampling", the sample size in this study amounted to 20 mothers then divided into 2 groups where 10 mothers as the experimental group and 10 mothers as the control group. Data collection is recorded on the observation sheet, data analysis is done by univariate and bivariate with t-independent test. The results of the analysis showed that there was an effect of Early Breastfeeding Initiation (EBI) on the amount of Bleeding Period IV in the Midwife Clinic Suherni Amd. Keb Kec Beringin Kab Deli Serdang in 2019 with a value of $p$ 0,000. It is expected that the number of mothers who breastfeed in the first minute to one hour of birth can increase, because EBI provides many benefits for babies and mothers. If immediately breastfeeding after giving birth can reduce maternal mortality.
\end{abstract}

Keywords: Early Breastfeeding Initiation, Post Partum Blood

\section{Pendahuluan}

United Nations Children's Fund (UNICEF) pada pekan menyusui (World Breastfeeding Week) 1-7 Agustus 2016 mengajak dunia untuk menyadari pentingnya melakukan Inisiasi Menyusu Dini (IMD) karena IMD memberikan banyak manfaat bagi bayi dan Ibu bersalin. Menurut Peraturan Pemerintah Nomor 33 Tahun 2012 dalam pasal 9 (1) disebutkan tenaga kesehatan dan penyelenggara fasilitas pelayanan kesehatan wajib melakukan IMD terhadap bayi yang baru lahir kepada ibunya paling singkat selama satu jam (Kemenkes RI, 2015). Inisiasi Menyusu Dini (IMD) sendiri masih rendah dilaksanakan di Indonesia. Berdasarkan data yang diperoleh dari Riskesdas tahun 2013 bahwa persentase IMD tertinggi di Provinsi Nusa Tenggara Barat (NTB) 
sebesar $52,8 \%$ sedangkan terendah di Provinsi Papua Barat sebesar 21,7\%. Cakupan IMD Nasional sebesar 34,5\% dan terdapat 18 Provinsi yang cakupannya dibawah angka Nasional. Sumatera Utara ikut menyumbang angka rendahnya pelaksanaan IMD yaitu $24 \%$. Perlu dilakukan upaya agar 18 Provinsi dapat meningkatkan nilai cakupannya, salah satunya dengan cara melakukan penyuluhan oleh Bidan dan tenaga kesehatan lainnya tentang IMD (Riskesdas, 2013).

Inisiasi Menyusu Dini (IMD) berkaitan dengan produksi hormon oksitosin, dimana hormon tersebut akan membantu rahim berkontraksi sehingga secara tidak langsung dapat mengurangi jumlah darah kala IV pada ibu. Diharapkan jumlah Ibu bersalin yang menyusui pada menit-menit pertama sampai satu jam kelahiran dapat meningkat, karena IMD memberikan banyak manfaat bagi bayi dan Ibu. Apabila segera menyusui setelah melahirkan dapat menurunkan kematian Ibu sebesar 17-22\% (Kemenkes RI, 2015).

Angka Kematian Ibu (AKI) merupakan salah satu indikator dalam menentukan derajat kesehatan masyarakat. Kematian Ibu adalah kematian selama kehamilan atau dalam periode 42 hari setelah berakhirnya kehamilan, akibat sebab yang terkait dengan atau diperberat oleh kehamilan atau penanganannya, tetapi bukan disebabkan oleh kecelakaan/cedera. Terdapat 536.000 Ibu meninggal akibat persalinan maternal terjadi di seluruh dunia. Kematian Ibu paling tinggi berada di negara berkembang sebanyak $99 \%$ dengan 450 kematian Ibu per 100.000 kelahiran hidup (World Health Organization, 2015).

Angka Kematian Ibu (AKI) di Indonesia masih tinggi. Berdasarkan data Kementerian Kesehatan Republik Indonesia 2015 tercatat ada 305 Ibu meninggal per 100 ribu orang. Menurut Direktur Jenderal Kesehatan Keluarga Kemenkes Eni Gustina, penyebab terbesar kematian Ibu di Indonesia selama tahun 2010-2013 adalah perdarahan 30,3\% (Kemenkes RI, 2015).
Untuk itu perlu adanya pencegahan dan upaya untuk menekan tingginya Angka Kematian Ibu (AKI). Departemen Kesehatan telah berupaya mengatasi kematian Ibu melalui kebijakan Asuhan Persalianan Normal (APN) sesuai dengan pendekatan Making Pregnancy Safer (MPS) yang diprakarsai oleh WHO. Salah satu kegiatan yang dilaksanakan dalam melaksanakan APN adalah IMD. Inisiasi Menyusu Dini (IMD) Salah satu cara yang sekarang sedang digencarkan oleh Kementrian Kesehatan Republik Indonesia. Dengan dilakukan IMD hormon alamiah oksitosin bisa mempercepat kontraksi uterus selepas bayi lahir sehingga membantu mengeluarkan plasenta dan mengurangi jumlah darah kala IV post partum.

Menurut penelitian stanton et al upaya penanganan perdarahan postpartum adalah dengan diberikan oksitosin, dimana oksitosin mempunyai peranan penting dalam merangsang kontraksi otot polos uterus sehingga perdarahan dapat teratasi.

Menurut Roesli (2013) manfaat IMD bagi ibu adalah mempercepat involusi uterus sehingga mengurangi jumlah darah kala IV post partum. Ini karena pengaruh hormon oksitosin ditandai dengan rasa mules karena rahim berkontraksi, hentakan kepala bayi ke dada ibu, sentuhan tangan bayi di puting susu dan sekitarnya, emutan dan jilatan bayi pada puting ibu merangsang pengeluaran hormon oksitosin.

Menurut Sumarah (2014) menyatakan bahwa IMD mempengaruhi jumlah perdarahan postpartum karena Kontraksi rahim setelah melahirkan sangat meminimalkan risiko perdarahan. Inisiasi Menyusu Dini (IMD) merangsang bagian belakang kelenjar hypofiche untuk menghasilkan oksitosin yang memicu kontraksi otot rahim sehingga resiko untuk prevalensi perdarahan postpartum dapat diminimalkan.

Berdasarkan studi pendahuluan yang dilakukan peneliti di klinik Bidan Suherni Amd. Keb, jumlah ibu bersalin normal periode Januari - Maret 2019 adalah 23 Ibu. Diketahui ada yang 
melakukan IMD dan ada yang tidak melakukan IMD. Sebagian Ibu post partum tidak mau melakukan IMD, karena Ibu mengeluhkan masih merasa lemas setelah bersalin sehingga tidak sanggup untuk menyusui. Berdasarkan wawancara pada Bidan Suherni Amd. Keb, dikatakan bahwa program IMD belum bisa dilaksanakan secara optimal karena ibu tidak bisa dipaksakan untuk melakukan IMD, akan tetapi setiap Ibu telah diberikan pengetahuan tentang pentingnya IMD dan Berdasarkan data yang diperoleh tafsiran tanggal persalinan di Klinik Bidan Suherni Amd. Keb, periode Mei - Juni berjumlah 20 ibu.

Berdasarkan data diatas, bahwa IMD dapat mengurangi jumlah darah kala IV post partum, dan program pelaksanaan IMD belum sepenuh nya tercapai, maka peneliti tertarik untuk melakukan penelitian di klinik Bidan Suherni Amd. Keb, dengan judul "Pengaruh Inisiasi Menyusu Dini (IMD) Terhadap Jumlah Darah Kala IV Persalinan Di Klinik Bidan Suherni Amd. Keb, Kec. Beringin Kab. Deli Serdang Tahun 2019",

\section{METODE}

Jenis penelitian ini yang digunakan yaitu pra eksperiment yaitu untuk mengidentifikasi pengaruh inisisasi menyusu dini terhadap jumlah darah kala IV. Desain ini menggunakan dua kelompok yaitu kelompok eksperimen dan kelompok kontrol kedua kelompok tersebut diberikan pretest. Kelompok eksperimen dilakukan IMD sedangkan kelompok kontrol tidak dilakukan IMD. Penelitian dilaksanakan pada Maret-Agustus 2019. Populasi dalam penelitian ini adalah seluruh ibu bersalin wilayah klinik bidan Suherni sebanyak 28 orang. Jumlah sampel sebanyak 20 orang yang terbagi menjadi 10 orang kelompok kontrol dan 10 orang kelompok intervensi. Penelitian ini mengambil sampel dilakukan dengan menggunakan purposive sampling.

Analisa data pada analisi univariat data yang diperoleh dari hasil pengumpulan data dapat disajikan bentuk tabel distribusi frekuensi frekuensi. Pengujiannya dilakukan menggunakan uji t-independent.

\section{HASIL}

bahwa $\begin{gathered}\text { Berdasarkan tabel diketahui } \\ \text { karakteristik }\end{gathered}$ berdasarkan usia mayoritas responden berusia 21-29 tahun sebanyak 12 responden $(60 \%)$. Berdasarkan tingkat pendidikan mayoritas responden berpendidikan SMA sebanyak 9 responden $(45 \%)$, sedangkan berdasarkan pekerjaan mayoritas responden yang bekerja sebagai IRT sebanyak 11 responden (55\%).

Tabel 1: Distribusi Responden berdasarkan karakteristik Responden

\begin{tabular}{|c|c|c|c|c|}
\hline No & Variabel & Kategori & $\mathbf{F}$ & $(\%)$ \\
\hline \multirow[t]{4}{*}{1} & Usia & $<20$ Tahun & 3 & 15 \\
\hline & & 21-29 Tahun & 12 & 60 \\
\hline & & >30 Tahun & 5 & 25 \\
\hline & & Total & 20 & 100 \\
\hline \multirow[t]{6}{*}{2} & Pendidi & SD & 3 & 15 \\
\hline & kan & SMP & 5 & 25 \\
\hline & & SMA & 9 & 45 \\
\hline & & DIPLOMA & 1 & 5 \\
\hline & & SARJANA & 2 & 10 \\
\hline & & Total & 20 & 100 \\
\hline \multirow[t]{4}{*}{3} & Pekerja & IRT & 11 & 55 \\
\hline & an & PNS & 2 & 10 \\
\hline & & $\begin{array}{l}\text { WIRASWAST } \\
\text { A }\end{array}$ & 7 & 35 \\
\hline & Total & & 20 & 100 \\
\hline
\end{tabular}

Berdasarkan tabel 2 diketahui bahwa mayoritas responden kelompok yang melakukan IMD jumlah darah kala IV yang darah $\leq 200$ cC sebanyak 10 responden ( $100 \%)$ dan minoritas jumlah darah kala IV yang darah $>200$ cc sebanyak 0 responden ( $0 \%)$.

Tabel 2: Distribusi responden berdasarkan jumlah darah responden kelompok intervensi.

\begin{tabular}{cccc}
\hline No & $\begin{array}{c}\text { Kategori } \\
\text { Jumlah Darah } \\
\text { Kala IV }\end{array}$ & F & (\%) \\
\hline 1 & $>200 \mathrm{cC}$ & 0 & 0 \\
2 & $\leq 200 \mathrm{cc}$ & 10 & 100 \\
\hline & Total & $\mathbf{1 0}$ & $\mathbf{1 0 0}$ \\
\hline
\end{tabular}


Berdasarkan tabel diatas diketahui bahwa mayoritas responden kelompok yang tidak melakukan IMD jumlah darah kala IV yang darah > 200 cc sebanyak 8 responden ( $80 \%$ ) dan minoritas jumlah darah kala IV yang darah $\leq 200$ cc sebanyak 2 responden ( $20 \%$ ).

Tabel 3: Distribusi responden berdasarkan jumlah darah responden kelompok kontrol

\begin{tabular}{cccc}
\hline No & $\begin{array}{c}\text { Kategori } \\
\text { Jumlah Darah } \\
\text { Kala IV }\end{array}$ & F & $\mathbf{( \% )}$ \\
\hline 1 & $>200 \mathrm{cc}$ & 8 & 80 \\
2 & $\leq 200 \mathrm{cc}$ & 2 & 20 \\
\hline & Total & $\mathbf{1 0}$ & $\mathbf{1 0 0}$ \\
\hline
\end{tabular}

Berdasarkan tabel 4 rata-rata jumlah darah kala IV responden yang melakukan IMD adalah 150,63 dengan standart deviasi 22,149. Sedangkan responden yang tidak melakukan IMD rata - rata jumlah darah kala IV adalah 166,09 dengan standart deviasi 21,580. Pada uji statistik didapatkan nilai $\mathrm{p}=$ 0,000 maka dapat disimpulkan bahwa ada Pengaruh inisiasi menyusu dini (IMD) terhadap jumlah darah Kala IV persalinan.

Tabel 4: Rata-rata Jumlah Darah Kala IV Responden Kelompok Kontrol dan Kelompok Intervensi

\begin{tabular}{cccccc}
\hline $\begin{array}{c}\text { Varie } \\
\text { bel }\end{array}$ & $\begin{array}{c}\text { Me } \\
\text { an }\end{array}$ & $\begin{array}{c}\text { Seli } \\
\text { sih } \\
\text { Me } \\
\text { an }\end{array}$ & SD & SE & $\begin{array}{c}\text { P } \\
\text { Value }\end{array}$ \\
\hline $\begin{array}{c}\text { Interv } \\
\text { ensi }\end{array}$ & 150 & 15, & 22, & 0,3 & 0,000 \\
& & 46 & 149 & 80 & \\
Kontr & 166 & & 21, & 0,3 & \\
ol &, 09 & & 580 & 53 & \\
\hline
\end{tabular}

\section{PEMBAHASAN}

Menurut Mubarak (2012), menyatakan perubahan yang terjadi akibat bertambahnya usia seseorang akan terjadi pada aspek fisik secara garis besar ada empat kategori yaitu perubahan ukuran, perubahan proporsi, hilang nya ciri - ciri lama dan timbulnya ciri - ciri baru.

Berdasarkan hasil penelitian dan didukung dengan teori Mubarak bahwa salah satu faktor yang menyebabkan adanya perubahan adalah usia karena hal tersebut dapat menimbulkan terlewatnya beberapa hal yang penting. Menurut Dalyono (2012), pendidikan dapat diartikan sebagai sebuah proses dengan metode - metode tertentu sehingga orang memperoleh pengetahuan, pemahaman. Pendidikan sehingga dapat membantu pengetahuan ibu tentang pengaruh IMD.

Berdasarkan hasil penelitian dan didukung dengan teori Dalyono bahwa semakin tinggi pengetahuan seseorang, maka tingkat pengetahuan dan pemahaman sesuatu hal akan semakin baik.

Menurut Sari dan Handayani (2012) jumlah darah kala IV normal pada ibu post partum yaitu kira - kira sebanyak 100 - 300 cc. Perdarahan ini disebabkan oleh lepasnya plasenta dari tempat implementasi hal ini menyebabkan pembuluh darah tempat plasenta melekat terbuka lebar. Apabila kontraksi tidak baik akan menyebabkan jumlah perdarahan meningkat. Dengan adanya kontraksi maka pembuluh darah yang terbuka akan tertutup kembali sehingga mengurangi jumlah perdarahan kala IV yang keluar.

Didukung dengan penelitian Kristanti (2014) bahwa jumlah perdarahan akan berkurang dengan dibantu oleh kontraksi yang terjadi di uterus. Kontraksi tersebut dapat dirangsang dengan melakukan masase fundus. Melakukan masase terlihat terlalu sederhana untuk mengurangi perdarahan yang menjadi penyebab kematian no 1 di dunia. Tetapi berbagai riset telah membuktikan bahwa dengan melakukan masase dapat merangsang kontraksi secara alami. Maka setelah kala III selesai di anjurkan untuk memasase uterus untuk merangsang kontraksi.

Sejalan dengan penelitian yang telah dilakukan dapat disimpulkan bahwa jumlah darah kala IV $\leq 200$ cc sebanyak 10 responden (100\%) hal ini bisa saja terjadi akibat kontraksi yang disebabkan 
oleh hormon oksitosin karena melakukan IMD.

Menurut Hikmah dan Yani (2015), kehilangan darah pasca persalinan yang masih dianggap dalam batas normal adalah maksimal 300 ml, jika darah lebih dari $300 \mathrm{ml}$ maka hal tersebut dapat berdampak tidak baik bagi ibu dan bayi. Dampaknya seperti ibu lemas, pusing dan kesadaran menurun dari kondisi sebelumnya dan syok hipovelemik. Menurut Dewi dan Rahayu (2010) yang menyatakan bahwa syok hipovolemik terjadi jika kehilangan darah sekitar $50 \%$ dari total jumlah darah ibu. Tanpa darah yang cukup atau pengganti cairan, dapat menyebabkan kerusakan irrevesible pada organ dan sistem tubuh.

Didukung oleh penelitian Purwati dan Trisnawati (2015) menyatakan bahwa faktor penyebab perdarahan yaitu atonia uteri dan beberapa faktor lainnya. Atonia uteri memiliki angka yang cukup tinggi terjadi yaitu sekitar $60 \%$ pada periode postpartum. Hal ini disebabkan karena tidak berkontraksinya uterus sehingga pembuluh darah yang terbuka tidak bisa tertutup dan jumlah perdarahan akan semakin meningkat. $\mathrm{Hal}$ ini sesuai dengan hasil penelitian ini bahwa jumlah darah kala IV sebanyak 8 responden > 200 cc (80\%). Hal ini bisa saja terjadi karena uterus yang kurang berkontraksi yang disebabkan oleh kurangnya hormon oksitosin karena tidak melakukan IMD.

Hasil penelitian ini sejalan dengan penelitian Ariesca (2012), dimana dalam penelitian ini didapatkan rata - rata jumlah darah responden kelompok intervensi adalah 302,70 cc dengan standart deviasi 32,64. Sedangkan pada responden kelompok kontrol adalah 340,04 cc dengan standart deviasi 28,35. Pada uji statistik didapatakan nilai $\mathrm{p}=0,000$ maka dapat disimpulkan bahwa ada perbedaan jumlah rata - rata darah responden kelompok intervensi dan responden kelompok kontrol . Dapat dilihat dari hasil penelitian menunjukkan bahwa IMD memiliki pengaruh yang signifikan terhadap jumlah darah post partum. Perdarahan ini dapat teratasi akibat adanya rangsangan kontraksi dengan melakukan IMD yang menghasilkan hormon oksitosin.

Sejalan dengan penelitian Sari dan Handayani (2012) menyatakan bahwa rata - rata jumlah darah kala IV persalinan pada ibu yang melakukan IMD di klinik BPS Ny .Hj Endang Purwati adalah 76,33 cc sedangkan rata - rata jumlah darah kala IV persalinan pada ibu yang tidak melakukan IMD adalah 131,00 cc. Dan perbandingan rata - rata jumlah darah kala IV persalinan pada ibu yang melakukan IMD dengan ibu yang tidak melakukan IMD adalah 54,67 cc. Pada uji statistic didapatkan nilai $\mathrm{p}=$ 0,000 Maka dapat disimpulkan bahwa adanya pengaruh IMD terhadap jumlah darah kala IV.

Menurut asumsi peneliti dapat disimpulkan bahwa pelaksanaan tindakan IMD berkaitan dengan produksi hormon oksitosin, dimana hormon tersebut akan membantu rahim berkontraksi sehingga secara tidak langsung dapat mengurangi jumlah darah kala IV post partum. Diharapkan jumlah Ibu bersalin yang menyusui pada menit-menit pertama sampai satu jam kelahiran dapat meningkat, karena IMD memberikan banyak manfaat bagi bayi dan ibu. Dengan melakukan IMD hormon alamiah oksitosin bisa mempercepat kontraksi uterus selepas bayi lahir sehingga membantu mengeluarkan plasenta dan mengurangi jumlah darah kala IV post partum.

\section{KESIMPULAN}

a. Kelompok ibu yang melakukan IMD. Mayoritas jumlah darah kala IV yang $\leq 200$ cc sebanyak 10 responden ( $100 \%$ ) dan minoritas jumlah darah kala IV yang >200 cc sebanyak 0 responden ( $0 \%$ ).

b. Kelompok ibu yang tidak melakukan IMD. Mayoritas jumlah darah kala IV yang > 200 cc sebanyak 8 responden (80\%) dan minoritas jumlah darah kala IV yang $\leq 200 \mathrm{cc}$ sebanyak 2 responden ( $20 \%$ ).

c. Rata - rata jumlah darah kala IV responden yang melakukan IMD adalah 150,63 dengan standart deviasi 22.149. sedangkan responden yang tidak melakukan IMD rata - rata jumlah darah kala IV 
adalah 166.09 dengan standart deviasi 21.580..

d. Uji statistik didapatkan nilai $\mathrm{p}=$ 0,000 artinya ada pengaruh Inisiasi Menyusu Dini (IMD) Terhadap Jumlah Darah Kala IV Persalinan Di Klinik Bidan Suherni Amd. Keb Kec Beringin Kab. Deli Serdang Tahun 2019.

\section{DAFTAR PUSTAKA}

Ariescha, Putri Ayu Yesi. 2012. Pengaruh Insiasi Menyusu Dini Terhadap Perdarahan Postpartum di Klinik Bersalin Tanjung Delitua. Repository.usu.ac.id. Diunggah tanggal 15 April 2019.

Dalyono. 2012. Psikologi Pendidikan. Jakarta: Rineka Cipta.

Dewi, Enita; Rahayu, Sri. 2010. Kegawatdaruratan Syok Hipovolemik. Berita IImu Keperawatan. Vol 2. No 2.

Hikmah, Nurul; Yani, Dian Puspita. 2015. Gambaran Haemoragic Post Partum Pada Ibu Bersalin dengan Kejadian Anemia di Ruang PONEK RSUD Kabupaten Jombang. Jurnal Edu Health. Vol 5. No 2.

Kemenkes. (2015). Penyajian Pokokpokok Hasil Riset Kesehatan Dasar 2013. Diperoleh dari www.kesga.kemenkes.go.id.

Diakses pada tanggal 22 Maret 2019.

Kemenkes. (2015). Profil Kesehatan Indonesia 2015. Diperoleh dari www.depkes.go.id. Diakses pada tanggal 18 Maret 2019.

Kristanti, Risma Aprinda. 2014. Pengaruh Oksitosin Terhadap Kontraksi Otot Polos Uterus. Jurnal Biologi El Hayah. Vol 5. No 1.

Mubarak, Iqbal; Wahit. 2012. Ilmu Kesehatan Masyarakat Konsep dan Aplikasi dalam Kebidanan. Jakarta: Salemba Medika.

Profil Kesehatan Indonesia Tahun 2017 diakses pada 25 Maret 2019.

Profil Kesehatan Provinsi Sumatera Utara Tahun 2017 diakses pada 25 Maret 2019.

Purwanti, Sugi; Trisnawati, Yuli. 2015. Determinan Faktor Penyebab Kejadian Perdarahan Post Partum Karena Atonia Uteri. Jurnal
Publikasi Kebidanan Akbid YLPP Purwokerto. Vol 6. No 1.

Riyanto, A (2018). Aplikasi metodologi penelitian kesehatan. Nuha Medika: Yogyakarta.

Roesli, Utami. 2008. Inisiasi Menyusu Dini Plus ASI Eksklusif. Jakarta: Pustaka Bunda.

Sari, Ni Made Maria; Handayani, Sri. 2012. Pengaruh Inisiasi Menyusu Dini Terhadap Jumlah Perdarahan Kala IV Persalinan di Klinik BPS Ny. Endang Purwati- MergangsanYogyakarta. Jurnal Kesehatan Samudra Ilmu. Vol 3. No 2.

Sumarah, et all. 2014. Pengaruh Insiasi Menyusu Dini Terhadap Jumlah Perdarahan Pasca Persalinan. Jurnal Kesehatan reproduksi. Vol 1. No 1. UGM. Yogyakarta.

World Health Organization.2015. Maternal Mortality. In: Reproduction Heald and Research, editor.Geneva. 